\title{
What really happened after Colorado legalized marijuana?
}

\author{
— Cite as: CMAJ 2018 October 15;190:E1237-8. doi: 10.1503/cmaj.109-5665
}

Posted on cmajnews.com on Sept. 26, 2018.

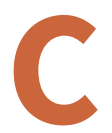
olorado often comes up in discussions about legalizing cannabis, either as a model or a cautionary tale. According to Andrew Freedman, the state's former marijuana czar, it's both.

For better or worse, it is unclear how much has changed in the five years since Colorado legalized cannabis, said Freedman at the recent Recovery Capital Conference in Toronto. It's too soon to know the long-term health impacts of the policy. However, there have been concerning increases in poisonings and fatal road accidents involving cannabis. And questions remain about heavy users and highly potent products.

There are also lessons for Canada, Freedman said, because Colorado's legal pot regime is "more in line with the commercialization that Canada is attempting" than other states. These lessons are often lost, however, in the polarized debate about legalization.

Teens do perceive marijuana as less risky now, but that doesn't appear to have affected their use, said Freedman. When it comes to teen use in the past 30 days, for example, "you will hear a lot of different statistics about what happened." Some cite a 20\% increase from 2011/12 to the beginning of legalization in $2013 / 14$. Others cite a 20\% decrease from 2012/13 to 2015/16. But overall, "we've seen almost statistically flatline use," said Freedman. "We've remained somewhere between $9 \%$ and $11 \%$ for the past decade."

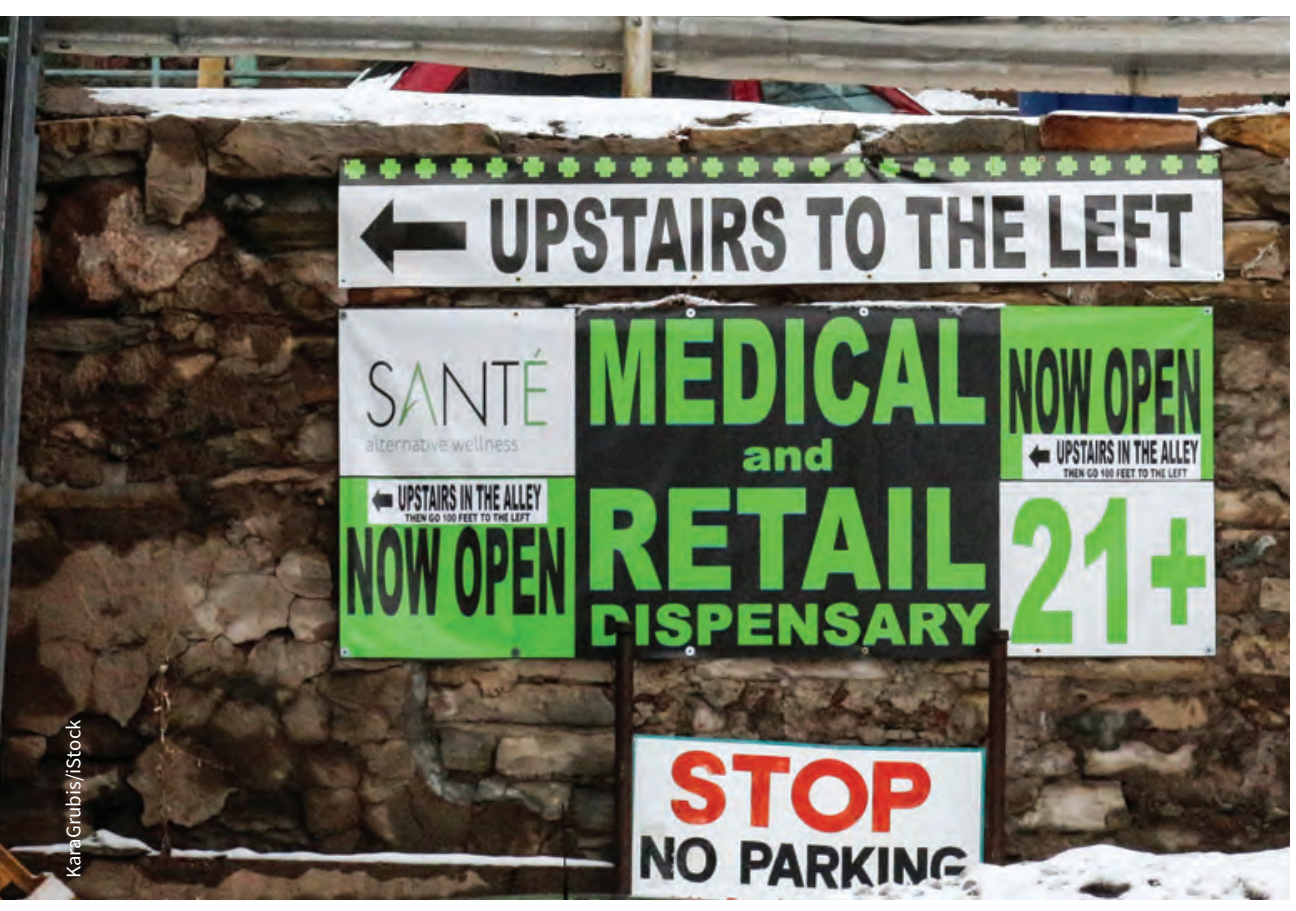

Legal pot advocates and critics alike cite data from Colorado to support their respective stances but may be missing the bigger picture.

There have been anecdotal reports about an increase in school suspensions involving drugs, but again, "we didn't see statistically significant changes," Freedman said. The data on suspensions aren't that useful, anyway, because it doesn't differentiate which drug was involved.

Although cannabis use among adults has increased, from more than $12 \%$ of the population in $2012 / 13$ to more than $16 \%$ in 2015/16, "we were surprised that the rate of change didn't change," Freedman said. Legalization didn't change prior trends showing that "Coloradans like marijuana and they like it more over time." The only statistically significant increase occurred among people over age 65 , likely because they're using the drug for pain relief.

The state was unprepared, however, for the risks posed by edible cannabis products to people who take too much by mistake. "They end up having an acute psychotic break and they're calling poison control and ending up in hospital," said Freedman. After a young tourist fatally jumped from a hotel balcony after consuming too many pieces of a cannabis cookie, the state introduced emergency regulations. These included dosing limits, warning labels, safer packaging, and bans on products that look like kids' candy.

At the peak of the problem, there were 230 poison control calls in a year. However, "the same year we got 6500 calls for alcohol poisoning," Freedman noted. "If you're looking where to spend resources, know that alcohol remains a bigger problem."

More troubling are the early trends in the percentage of drivers involved in fatal accidents who test positive for tetrahydrocannabinol (THC), the principal 
psychoactive component of cannabis. That percentage has doubled since legalization, from $10 \%$ of all drivers involved in fatal crashes in 2013 to $20 \%$ in 2016. Freedman noted that the data aren't conclusive. It doesn't tell you if a driver was high, since THC can stay in the blood for up to a month, and it doesn't tell you if marijuana caused the accident, he explained. Nevertheless, "I think we have a problem here."

The marijuana industry has pushed backed on these concerns, citing studies that show people drive slower while high. "I think this is one of the places where industry behaved irresponsibly," Freedman said. "People driving 10 kilometers under the speed limit on the highway are a danger."
The state has also struggled in finding the right messages to educate the public about the risks of using cannabis. An initial campaign that warned "don't be a lab rat" was panned as a return to the condescending rhetoric of the war on drugs. A later campaign that asked students to consider if cannabis would help them achieve their goals was more successful. Surveys showed youth "not only retained that message but were less likely to engage in marijuana use," Freedman said.

Another frustration is the lack of data on daily and heavy use of cannabis. Twenty percent of marijuana users account for $80 \%$ of consumption, Freedman said. For industry, "the only way to grow the market is to get that twenty percent to use more or to start using at a younger age," he explained. "Everything we learned in tobacco and alcohol will apply here, but groups have to galvanize early and understand that this is an ongoing battle that's coming."

The fact that there are no checks on the potency of cannabis products in Colorado "remains a big problem," Freedman said. Most cannabis research uses products with much lower potency than those used recreationally. Some concentrated products can be $80 \%$ or $90 \%$ THC by volume, but are regulated the same as less potent products, Freedman explained. "It's really something that Canada is going to have to lead the way on."

Lauren Vogel, CMAJ 